\section{An unusual cause of bilateral diaphragmatic paralysis}

\author{
A Pandit, S Kalra, A Woodcock
}

\begin{abstract}
In a patient who had a sudden onset of bilateral diaphragmatic paralysis after forceful neck manipulation complete, though gradual, recovery in lung function and transdiaphragmatic pressures was seen over three years. This is a previously unrecognised risk of neck osteopathy.
\end{abstract}

Bilateral diaphragmatic paralysis may follow phrenic nerve injury. The phrenic nerve arises from the spinal roots of the $3 \mathrm{rd}, 4 \mathrm{th}$, and 5 th cervical segments and emerges on the anterior surface of the scalenus anterior. It enters the thorax in front of the subclavian artery and behind the subclavian vein. We report a case of bilateral diaphragmatic paralysis due to forceful neck manipulation.

\section{Case report}

In February 1988 a 69 year old retired insurance agent developed pain in his shoulders. He saw an osteopath (a man weighing $100 \mathrm{~kg}$ ) at $6.30 \mathrm{pm}$. The patient was asked to lie prone and the osteopath applied extreme pressure with his thumbs on both sides of the

Regional Department of Respiratory Physiology,

Wythenshawe

Hospital, Manchester

M23 9LT

A Pandit

$S$ Kalra

A Woodcock

Reprint requests to

Dr Pandit

Accepted 12 August 1991 patient's neck posteriorly and with his fingers anteriorly. He forcefully abducted, adducted, flexed, and extended the patient's neck continuously for 20 minutes. Immediately after the session the patient was breathless. Two and a half hours later he went to bed and was unable to lie flat owing to severe breathlessness, which improved when he sat up. He had smoked heavily ( 80 pack years) until a year before presentation.

Serial lung function measurements from April 1988 to January 1991

\begin{tabular}{|c|c|c|c|c|}
\hline & Predicted & April 1988 & August 1989 & January 1991 \\
\hline \multicolumn{5}{|l|}{$\mathrm{FEV}_{1}(1)$} \\
\hline Standing & $3 \cdot 0$ & $1 \cdot 2$ & $1 \cdot 45$ & 1.6 \\
\hline Lying & & 0.5 & $1 \cdot 0$ & $1 \cdot 3$ \\
\hline \multicolumn{5}{|l|}{ FVC(1) } \\
\hline Standing & $4 \cdot 0$ & $1 \cdot 7$ & $2 \cdot 2$ & $2 \cdot 4$ \\
\hline Lying & & $0 \cdot 8$ & $1 \cdot 8$ & $2 \cdot 0$ \\
\hline \multicolumn{5}{|c|}{ Pressures ( $\mathrm{cm} \mathrm{H}_{2} \mathrm{O}$, sitting) } \\
\hline Pimax & $>44$ & 35 & 50 & 52 \\
\hline Pemax & $>80$ & 200 & 148 & 141 \\
\hline Sniff Pdi & $>100$ & 12 & 46 & 133 \\
\hline
\end{tabular}

FEV -forced expiratory volume in one second; FVC-forced vital capacity; Pimax-maximal inspiratory mouth pressure; Pemax-maximal expiratory mouth pressure; Pdi-transdiaphragmatic pressure.

He was seen a fortnight after the neck manipulation. At this time he was mildly breathless when standing but became extremely breathless and cyanosed on lying flat, with paradoxical movement of the abdomen on inspiration. Neurological examination showed no abnormality.

The chest radiograph showed raised bilateral hemidiaphragms. A cervical spine radiograph was unremarkable. His biochemical profile, muscle enzymes, acid maltase, virus antibody titres, and echocardiogram were all normal.

Lung function tests (table) showed a restrictive pattern with low single breath carbon monoxide transfer factor $(5.8 \mathrm{mmol}$ (normal $8 \cdot 8) \mathrm{mmol} / \mathrm{min} / \mathrm{kPa}$ ) and high transfer coefficient values $(2.0$ (normal 1.7$) \mathrm{mmol} \mathrm{min} / \mathrm{kPa} /$ 1). Vital capacity fell by $53 \%$ when he lay supine. Maximal inspiratory mouth pressure was low, but expiratory pressure was normal. ${ }^{1}$ The maximal sniff transdiaphragmatic pressure (Pdi) was very low (12 (normal > 100) $\mathrm{cm} \mathrm{H}_{2} \mathrm{O}$ ). Percutaneous stimulation of the left and right phrenic nerves produced no electrical response from the diaphragm, confirming bilateral diaphragm paralysis.

Over the next three years there was a gradual improvement in symptoms, vital capacity, and transdiaphragmatic pressures. By 1991 the transdiaphragmatic pressures were normal, with a maximal sniff Pdi of $133 \mathrm{~cm} \mathrm{H}_{2} \mathrm{O}$.

\section{Discussion}

This case emphasises the importance of considering diaphragm weakness in patients presenting with orthopnoea. Bilateral phrenic nerve palsy is known to occur after thoracic and cervical spine surgery ${ }^{2}$ and blunt chest trauma and in multiple sclerosis, anterior horn cell disease, peripheral neuropathies, muscular dystrophies and myopathies. The function of phrenic nerves and diaphragm recovers if the nerve injury is not permanent. Neuralgic amyotrophy has been rarely reported as a cause for diaphragm weakness. ${ }^{3}$ The time relationship between the onset of symptoms and the neck manipulation, however, and the absence of any other neurological deficit strongly suggests that the phrenic nerves in this patient were injured by forceful neck manipulation. We presume that the nerve was compressed rather than transected as complete but gradual recovery occurred over three years.

We are grateful to Dr David Mulvey, Royal National Heart and Lung Hospital, Brompton, London, for the initial studies on diaphragm function.

1 Wilson SH, Cooke NT, Edwards RHT, Spiro SG. Predicted normal values for maximal respiratory pressures in caucasian adults and children. Thorax 1984;39:535-8.

2 Spiteri MA, Mier AK, Brophy CJ, Pantin CFA, Green M. Bilateral diaphragm weakness. Thorax 1985;40:631-2.

3 Graham AN, Martin PD, Haas LF. Neuralgic amyotrophy with bilateral diaphragm weakness. Thorax 1985;40: 635-6. 